\title{
A METHODOLOGICAL FRAMEWORK FOR ORGANIZATIONAL RISK MANAGEMENT IN ENERGY COMPANIES
}

\author{
L.D. GITELMAN, L.M. GITELMAN \& M.V. KOZHEVNIKOV. \\ Ural Federal University, Russia.
}

\begin{abstract}
Energy production has always been associated with a number of operational (technological) risks as well as risks resulting from external events. A large number of tools has emerged recently that utilize complex software solutions to minimize such risks, which shows in a significant reduction of failures at energy facilities in the past few years and a growth in the key performance indicators of energy businesses. The most difficult ones to assess and prevent are organizational risks. The probability of such risks increases alongside the progress of structural transformations in the global energy sector. Such risks, despite their internal nature, are capable of triggering serious deformations within the governance system of an energy company and, given the specific features of the energy sector, lead to a sharp performance drop across the industry. The article presents a methodological framework for operational risk management in energy companies that is based upon the idea of identifying the priority results of companies' performance. The proposed methodology is essentially about forming the risk space of an energy company and using it as a basis for quantitative assessment of the probability of risk events. This will in turn make it possible to identify critical organizational risks, assess anticipated damage and think of preventive management impact to offset the risk events.

Keywords: energy companies, innovation, organizational risks, reliability of power supplies, space of risk, transformation management
\end{abstract}

\section{INTRODUCTION}

When operating in competitive markets, energy companies have to make decisions in situations of relative uncertainty, which is fraught with certain risks that prevent them from reaching their goals. These are, above all, market (price) risks. In a situation of price uncertainty, the effectiveness of the energy company's operations depends on the professionalism of its management and on the market infrastructure, namely on the availability of mechanisms that make it possible to hedge the risks with the help of derivatives. As the industry gets increasingly liberalized and attractive to investors, financial (interest rate and currency) risks become more pronounced. It is also worth mentioning that non-financial risks are manifested in the inertia and resistance to change of the social and political environment and in some cases - in the open resistance of large consumers, regional authorities and other actors [1-3].

The hardest to gauge are organizational risks, namely the risks that have to do with structural changes at the industry level or in individual energy companies. The reason is the complete lack of statistics on the results and effects of organizational innovations because originally such decisions are not aimed at obtaining specific financial and economic results that can be quantified, that is, measured in numbers. The question is about profound changes to the ideology and technology of management that affect the fundamentals of corporate philosophy and imply the re-engineering of all key business processes in a company. At the same time, ensuring the reliability and security of electricity supply is top priority. In other words, the effectiveness of organizational transformations in power engineering is largely mediated by technological progress. 
Studies conducted by international consulting companies McKinsey, Aberdeen Group, Deloitte, Protiviti and others [4-9] confirm the growing importance of organizational risk management in the energy industry. In particular, a survey [5] done in 2015 by Aberdeen Group's specialists among 200 heads of energy companies revealed that nearly $60 \%$ of respondents cited organizational and operational risks to be priority ones (Fig. 1). In the latest annual report of Protiviti's [7] dedicated to the identification of significant risks that threaten the activities of energy companies, the largest number of risks were classified as strategic and organizational, associated with the introduction of innovation, corporate changes, restructuring of management systems, etc. (Fig. 2).

The article is a study of the methodological principles of risk management in the process of radical organizational transformation of a systemic nature that aim to take corporate governance in an energy company to a whole new level.

Compliance with new and / or changing regulatory requirements

Unpredictable global economic environment / market instability

Need to grow the business without increasing risk

Need to reduce the impact of organizational and operational risks



- Energy Respondents

Percentage of Respondents, $n=187$ Source: Aberdeen Group, June, 2014

Figure 1: Energy companies' risks allocation in order of importance [5].

Our organization/s succession challenges and ability to attract and retain top talent may limit our ability to achieve operational targets

Resistance to change may restrict our organization from making necessary adjustments to the business model and core operations

Our organization may not be sufficiently prepared to manage cyberthreats that have the potential to significantly disrupt core operations and/or damage our brand

Economic conditions in markets we currently serve may significantly restrict growth opportunities for our organization

Regulatory changes and heightened regulatory scrutiny may affect the manner in which our products or services will be produced or delivered

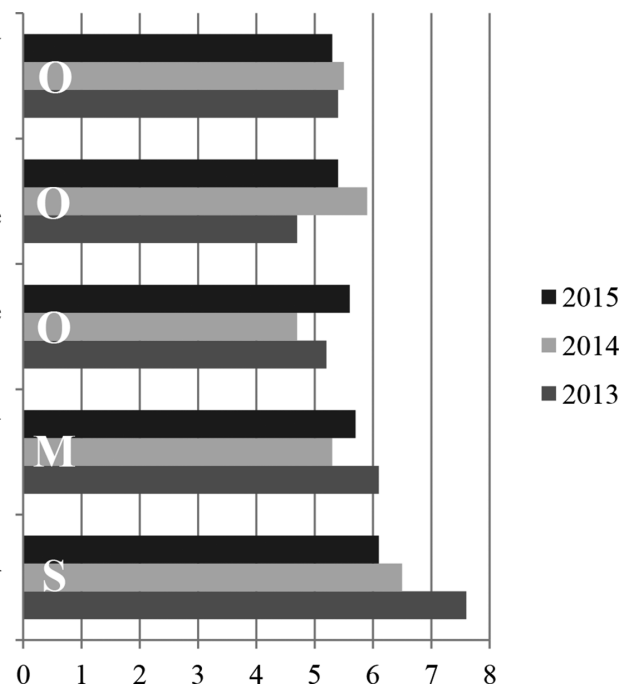

Figure 2: Energy companies' top risks for 2015, O - organizational and operational risks, $\mathrm{M}$ - macroeconomic risks, $\mathrm{S}$ - strategic risks [7]. 


\section{ISSUES OF ORGANIZATIONAL RISK STRUCTURATION}

The approaches that some scholars $[10,11]$ take to risk classification are directly or implicitly based on events associated with the risks, despite the fact that such events may not always be specific. There is no doubt that specific possible levels of risk have a certain objective foundation, i.e. a totally of causes that can each be considered as a risk event.

Content-wise, the interpretation of risk events is usually limited to the description of possible damage in case accidental problems occur (financial, investment, technological, operational, or organizational ones). This is probably the reason why many researchers stick to the view that many actual situations lack the statistical stability of risk events. Consequently, the stochastic apparatus cannot be used for the description of a risk and one has to limit oneself to the notion of 'uncertainty' with all the relevant computational schemes [12]. For risk events that are associated with organizational transformations the level of uncertainty is the highest, which calls for their careful structuration.

It is advisable to analyze the organizational risks of energy companies in line with successive risk events of two types: those related to deformations in the management system (Level 1) and those related to a decline in the energy company's performance outcomes (Level 2). Consequently, primary risks include personnel, operational and regulatory risks, while secondary ones include technological, economic and commercial risks. The study [13] created a classification of organizational risks that enabled the authors to introduce the notion of 'risk environment' that is defined as a specific environment of implementing the processes of strategic organizational innovation (Fig. 3).

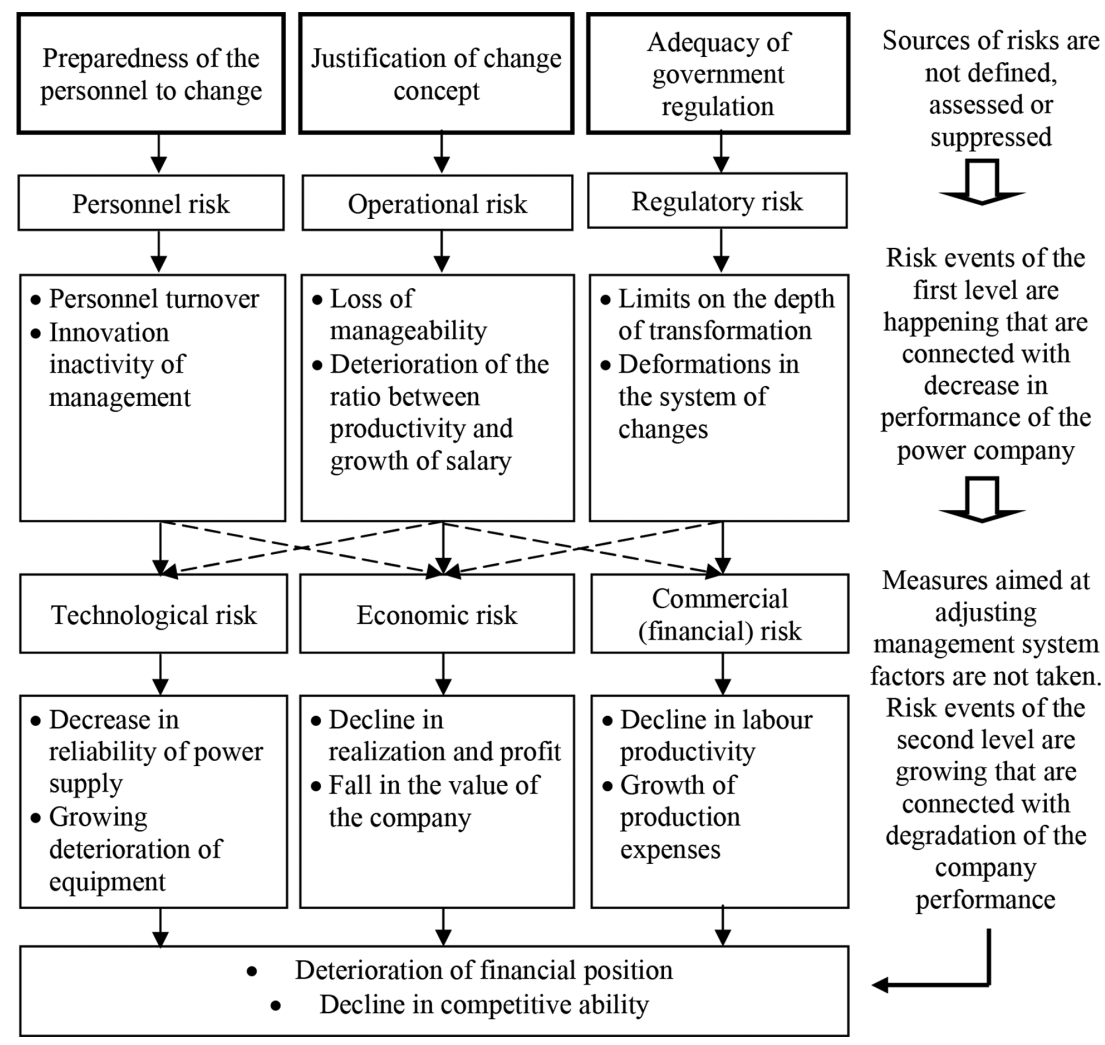

Figure 3: Model of structure of risk environment [13]. 
On the basis of the model of risk environment a method of structural risk assessment is created and a relevant mechanism for suppressing it is formed.

The risk of structural decision (innovation) of a radical type (in our classification it is a systemic risk) should be understood as a probabilistic threat of deterioration of the results of the company. Using the classification of risks and the model of risk environment, the following method of defining a systemic risk can be offered:

$$
R_{j}=N_{i} \cdot P_{i} \cdot P_{j i}
$$

where $\mathrm{R}_{\mathrm{i}}$ - risk of deterioration of the final result $j$ of the power company (or occurrence of $j$ type event); $\mathrm{N}_{\mathrm{i}}$ - power of the risk source of $i$ type event, preceding $j$ type event and acting as its factor ( $j$-type event is related to a decrease in efficiency of management system in the power company); $\mathrm{P}_{\mathrm{i}}$ - probability of decrease of event $i$; $\mathrm{P}_{\mathrm{ji}}$ - probability of fulfillment of the event $j$ under the influence of an actualized event $i$.

It has to be noted that at the preliminary stage of structuring, risk events should be presented as a totality of elementary outcomes in order to provide grounds for analysis of uncertainty associated with each element. Such dissection can be done using available retrospective data, the experience and expertise of specialists, analogy methods, model analysis, etc. Along with the structuration of information about risks and on the basis of such information the portfolio of risk management measures could be specified by constructing programs that provide a plan of action in certain situations. The practical value of such work is obvious - the successful elimination of risk situations is a prerequisite for future financial stability and one of the critical functions of management.

\section{QUANTITATIVE ASSESSMENT OF ORGANIZATIONAL TRANSFORMATION RISKS}

Analysis of individual risk events and groups of events is an essential instrument for the development of future transformation programs. It improves the reliability of solving a time-aligned sequence of problem situations, to substantiate the relevance, overlapping and convergence of associated risk events, creates conditions for building possible scenarios and variants of situation programs. The agenda of an analytical study includes the following questions:

- the long-term consequences of current risk events;

- the possibility of active influence on anticipated threats;

- the required structure of situational programs;

- building a system of priorities that makes it possible to rationally distribute resources and target measures among current and potential risk events.

Such analysis is performed not only in terms of trends and dynamics of relations, market connections and changes to the organizational structure of management in an energy company, but also in terms of final quantified performance indicators: expected lost revenue, production technology setback, lower labor productively growth, lower profitability growth, quantitative indicators of energy output.

We shall consider one of the possible variants in the initial stage of structuring organizational risks in an energy company, assuming that their comprehensive analysis confirms the possibility of applying the methods of probability analysis and quantitative assessment for a specific forecasting period. The place of the process of quantitative assessment of risk events in an energy company within the framework of the general risk management sequence (risk programming) is displayed in Fig. 4. 




Figure 4: Links between stages of risk management.

The situation is further complicated by the unique character of each new organizational decision. This calls for the use of a priori and indirect expert assessments that are based on the analysis of the financial and economic situation in the energy company, of the personnel's readiness to modernization, the level of elaboration in transformation projects, the managers' awareness about upcoming sector reforms etc. [14, 15].

To perform quantitative assessment of organizational risks, it appears most reasonable to employ the method of expert (biased) estimation of negative deviations that often takes the form of the scenario approach for the purposes of prediction calculations [16, 17]. The basic scheme builds upon an expert (simple of weighted) estimate of the probability of each scenario and constructing the expected value of a result.

For the purposes of this article we will only consider ways of using expert estimation to determine the most probable damage level from risk events and the most probable level of damage reduction by means of risk programming. The latter implies the availability and application of damage reduction or risk prevention programs (reducing the probability of risk occurrence).

We shall proceed from an assumption that a group of experts have presented with a task of assessing the probability of risk events. The structure of the event has already been established; they are considered to be independent and compatible. It is not ruled out that a risk event could be a totality of dependent elementary events. The experts have got detailed descriptions of each risk event as well as the composition and content of measures aimed at eliminating relevant risks. When structuring the risks, the analytical assessment of financial losses that could be brought about by each event was done. The product of such assessment is three possible scenarios (variants) of risk consequences - an optimistic, a pessimist and a neutral one. The immediate goal of the expert assessment within the framework of the first scheme is:

- to assess the probability of each risk event being considered;

- to determine the relevance of each risk;

- to estimate mean expected losses in each scenario.

The first task is solved in a traditional way by calculating mean probability assessments for each risk event. When such assessments are used, the results depend on the makeup of the group of experts and the number of experts. It should also be taken into account that under certain conditions (e.g. a comparable level of the competence of experts, the availability of information on the issue, a multi-phased assessment procedure), the distribution of general populations will be close to normal. 
An indirect proof of this hypothesis is its interpretation within the context of the theory of measurement error. If the hypothesis is rejected, a method is typically used that originates from network simulation and assumes that an expert assessment of random variable $\xi$ has the $\beta$-distribution:

$$
\xi=\frac{1}{6}\left(\xi_{\min }+4 M|\xi|+\xi_{\max }\right)
$$

Expected value estimation (2) that is typically used in such cases is not always trustworthy because the possible error of the expert assessment of the most likely value of random variable $\xi$ grows four-fold [18].

On the other hand, the parameters of the $\beta$-distribution could be close to normal and the application of the hypothesis of the normal distribution does not add much error to the calculations. An example of mean expert assessment calculations can be found in Table 1.

The second and the third tasks are dealt with in parallel. The first step is to map risk situations considering the compatibility of original risk events. To do that, it is necessary to compute all possible risk situations that are described by the functions $C_{n}{ }^{1}, C_{n}{ }^{2}, C_{n}{ }^{3}, \ldots, C_{n}{ }^{n}$, where $n$ is the number of original risk events.

An example of such a map for $n=4$ is depicted in Fig. 5. Mapping risk situations could be automated with the help of simple software. Such maps help calculate the probability of situations (probability of co-occurence of original independent events). As a result of constructing a map of risk situations and introducing an additional conventional ('zero') event that signifies all events in the population that are accepted as 'absence of risk', we get a complete group of alternative (transformed) events.

Expected damage from the occurence of certain risk events can be determined using the algorithm in Fig. 6. The sequence of calculations includes the following steps.

1. Building a population of independent alternative risk events.

2. Expert assessement of the probability of risk events.

Table 1: Assessment of the probability of risk events.

\begin{tabular}{lllll}
\hline & \multicolumn{4}{c}{ Risk events } \\
\cline { 2 - 5 } Experts & $\mathrm{R} 1$ & $\mathrm{R} 2$ & $\mathrm{R} 3$ & $\mathrm{R} 4$ \\
\hline E1 & 0,7 & 0,35 & 0,2 & 0,3 \\
E2 & 0,65 & 0,38 & 0,25 & 0,31 \\
E3 & 0,6 & 0,4 & 0,22 & 0,35 \\
E4 & 0,55 & 0,29 & 0,28 & 0,29 \\
E5 & 0,62 & 0,32 & 0,19 & 0,33 \\
E6 & 0,58 & 0,39 & 0,24 & 0,34 \\
E7 & 0,5 & 0,25 & 0,25 & 0,28 \\
E8 & 0,64 & 0,36 & 0,21 & 0,27 \\
E9 & 0,65 & 0,23 & 0,27 & 0,32 \\
E10 & 0,72 & 0,34 & 0,18 & 0,25 \\
The mean & 0,621 & 0,331 & 0,229 & 0,304 \\
Dispersion & 0,00443 & 0,00339 & 0,00117 & 0,00103 \\
Coefficient of variation, \% & 0,71 & 1,02 & 0,51 & 0,34 \\
\hline
\end{tabular}


3. Identifying analytical measures of damage for each scenario outcome of using the situational program, and for each risk event.

4. Expert assessment of conditional probabilities in each scenario for every risk event occuring.

5. Assessment of the probability of damage in each situation (in each scenario).

6. Estimation of expected average damage in each situation; identifying the validity of the situations and their ranking.

7. Estimation of average total damage for each risk event and average damage in total.

It can be concluded that using expert assessment makes it possible to assess and structure the validity (threat) of possible risk situations within the framework of the described algorithm (risk situation - co-occurence of risk events).

Database of combinations

Risk events

1
2
3
4
2 continuation
3 continuation

\begin{tabular}{|c|c|c|c|c|c|c|}
\hline $\mathrm{R} 1$ & $\mathrm{R} 2$ & R3 & $\mathrm{R} 4$ & 4 & & \\
\hline $\mathrm{R} 1$ & $\mathrm{R} 2$ & $\mathrm{R} 1$ & R3 & $\mathrm{R} 1$ & R4 & \\
\hline R1 & $\mathrm{R} 2$ & R3 & R1 & $\mathrm{R} 2$ & $\mathrm{R} 4$ & \\
\hline R1 & $\mathrm{R} 2$ & R3 & $\mathrm{R} 4$ & 1 & & \\
\hline $\mathrm{R} 2$ & $\mathrm{R} 3$ & $\mathrm{R} 2$ & R4 & R3 & R4 & 6 \\
\hline $\mathrm{R} 1$ & $\mathrm{R} 3$ & $\mathrm{R} 1$ & $\mathrm{R} 2$ & R3 & R4 & 4 \\
\hline
\end{tabular}

Figure 5: Mapping risk events (the last two lines of the map show the continuation of the combinations of risk events: co-occurence of two and three risk events).

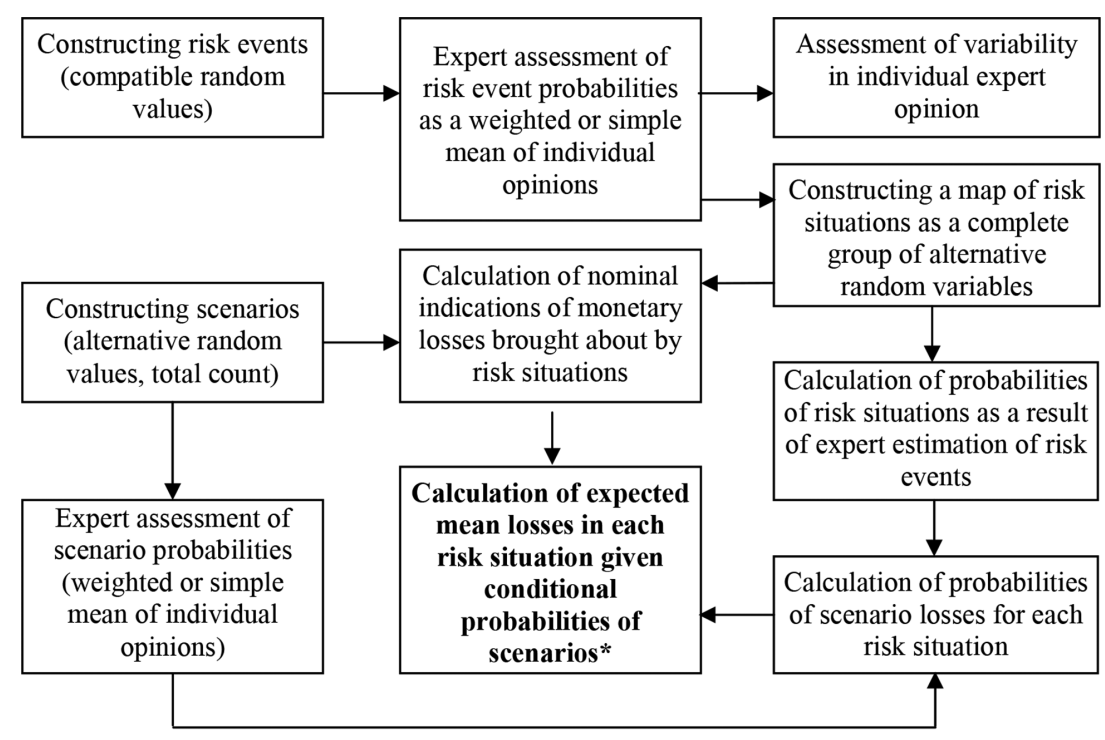

*Calculation of final characteristics of risk (scenarios are viewed as possible outcomes of using situational programme):

- relative validity of risk situations;

- ranking of risk situations;

- average expected losses in each scenario;

- indicator of mean total losses.

Figure 6: Algorithm of cost of risk (damage) assessment. 


\section{KEY ORGANIZATIONAL RISK MANAGEMENT PROVISIONS IN ENERGY COMPANIES AND WAYS OF MINIMIZING ORGANIZATIONAL RISK}

Figure 7 shows a basic scheme for managing the risks of strategic organizational transformations in an energy company. It is based on the following premises:

- risk management has to be organized as a continuous process including three stages: preparation, implementation of changes and final stage;

- risk management must be carried out in application to specific stages of transformation;

- the results of preliminary risk assessment provide grounds for deciding on the reasonability and forms and methods of handling specific kinds of risks;

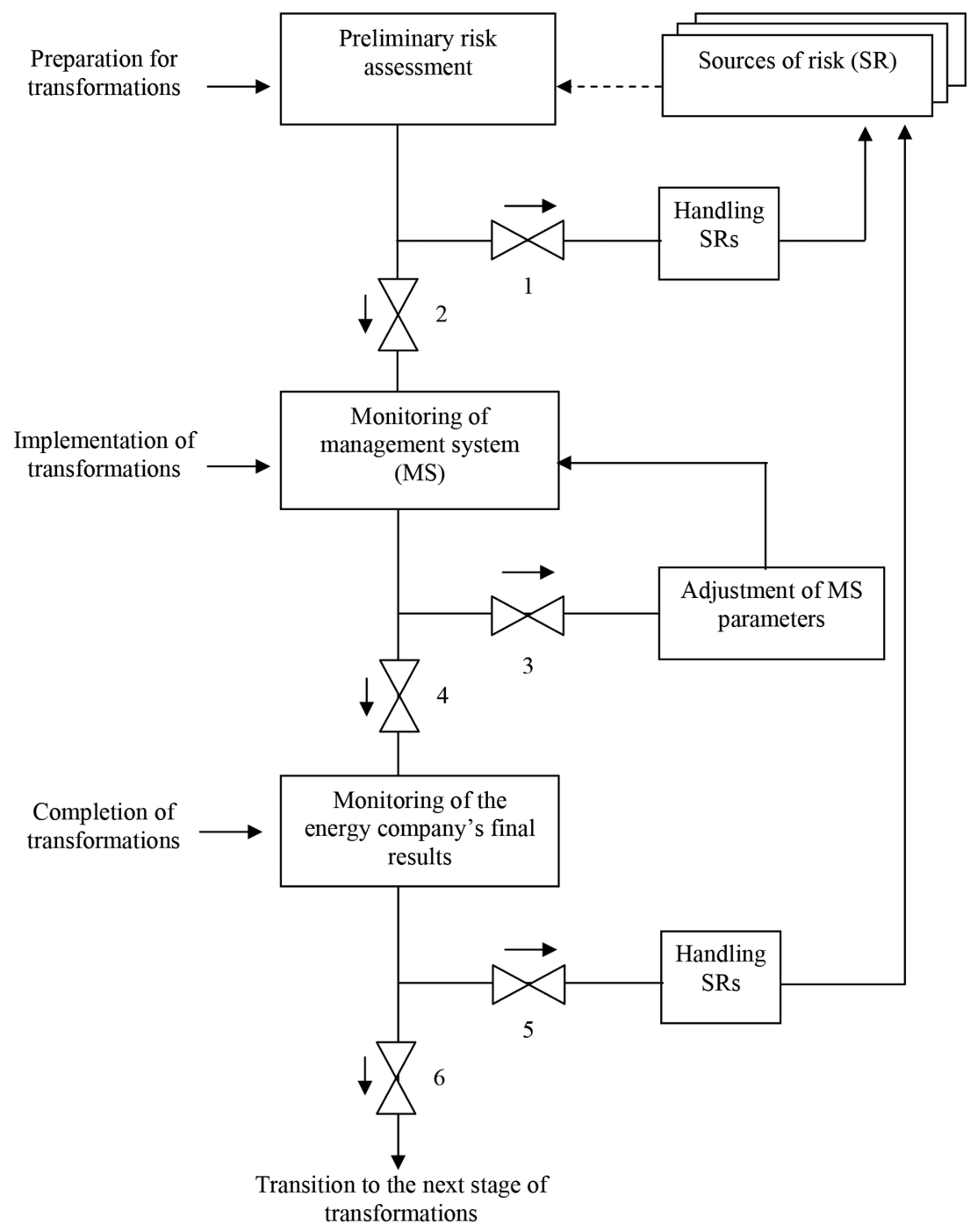

Figure 7: Scheme of organizational risk management at every stage of transformations: 1 - 6

- conventional 'valves' that regulate the sequence of steps. 
- in the course of transformations, the monitoring of the main factors of the company management system is carried out in order to detect symptoms of risk events of the first level (staff turnover, loss of controllability, blunders in the system of incentives, regulatory deformations etc.) and to make necessary adjustments. This is caused by the instability of the sources of risk and their ability to 'come to life' with the time after being suppressed;

- at the end of the first stage, comprehensive control of all final results is carried out and a decision is made whether to move on to the second stage. It may turn out that the durability of the sources of risk will call for additional actions;

- to address the tasks of risk management, independent experts should be employed, with all the essential information being provided to them.

Training for personnel, especially managers at all levels, to prepare them for the upcoming change should be considered as the most universal and effective way to minimizing structural risks. It is also necessary to substantiate the concept of changes and its implementation program in the most detailed way.

It is advisable to start the transformations with less 'risky' measures, following the pyramid principle. It will enable the team of innovation managers to 'warm up' by dealing with increasingly difficult tasks and accumulating experience in decision making.

When implementing the program of transformations it is necessary to closely monitor the interim results of the newly introduced ways of working in order to be able to make timely adjustments to the innovation process and prevent serious disruptions or failures. At the same time, it is necessary to monitor the environment, paying special attention to the behavior of consumers, competitors and, in particular, of regulators. For this purpose, the best method of risk minimization is by maintaining regular and reliable contact communication with these bodies.

\section{CONCLUSIONS}

The timely assessment of the sources of risks, 'getting in touch' with them and their effective neutralization at the stage of preparation for transformation as well as the identification of real threats that emerge in the course of transformation together will create a methodological framework for managing the risks of strategic organizational decisions in energy companies.

The proposed schemes and approaches to the analysis of risk events ensure their simultaneous and comprehensive assessment, make it possible to improve the accuracy of expert forecasts, and increase the controllability of organizational risks. All of this is possible thanks to the following:

1. The accumulated and well-structured information about risky events provides a wider range of factual and analytical data that are used for expert procedures.

2. The creation and expansion of an information base associated with the results of retrospective decisions makes it possible to improve the principles of designing situational loss control programs at present and in the future.

3. Approaches that have been traditionally used for expert analysis of risk management processes at the level of the energy company are usually good enough at accounting for the instability of technical and economic parameters of production and sales. But the absence of advanced analytical modules that would characterize loss from risk events, the local nature of management problems being analyzed, the distorted representation of the true development objectives and an overwhelming focus on prescriptive levers in 
loss control programs and measures being developed trim the possibility of obtaining reliable results.

4. In order to arrange the process of the assessment of risk events it is necessary to ensure constructive cooperation among experts (system analysts), managers of energy companies, sector ministries and representatives of government. Apparently, the effectiveness of the process will depend on the state of the information infrastructure in the industry that should support high communication dynamics. The research will make it possible to fine-tune the general concept of current and strategic management and work out conditions for an effective alignment of interests.

5. Provided they are refined accordingly and brought up to date, the proposed methods and calculation algorithms could be useful for managing specific business processes in energy companies that are strongly connected with risk. In general, studies of organizational risks could make it possible to refine the general concept of strategic management at the level of the industry and to work out conditions for an effective alignment of interests of stakeholders when conducting large-scale reforms.

\section{ACKNOWLEDGEMENT}

The work was supported by Act 211 Government of the Russian Federation, contract No 02. A03.21.0006.

\section{REFERENCES}

[1] Ruchkin, A., Fingert, A. \& Neiman, E., Risk management in the electricity industry: organizational issues and major risks of European energy companies, [in Russian]. Energy Market, 2, pp. 41-46, 2008.

[2] Zubakin, V., Risk management in energy companies: market approach, [in Russian]. Energy Market, 5, pp. 14-16, 2005.

[3] Gitelman, L.D., Russian power sector reform: lessons for developing countries. WIT Transactions on Ecology and the Environment, 190, pp. 19-26, 2014. https://doi.org/10.2495/EQ140031

[4] Heiligtag, S., Schlosser A. \& Stegemann, U., Enterprise-risk-management practices: Where's the evidence? A survey across two European industries, McKinsey \& Company, 2014, available at https://www.google.ru/url?sa=t\&rct=j\&q=\&esrc=s\&source= web\&cd=1\&ved=0ahUKEwjd5K3r59PKAhVi1XIKHRtMDYQQFggbMAA\&url=ht tp $\% 3 \mathrm{~A} \% 2 \mathrm{~F} \% 2 \mathrm{Fwww}$.mckinsey.com $\% 2 \mathrm{~F} \% 2 \mathrm{Fmedia} \% 2 \mathrm{Fmckinsey} \% 2 \mathrm{Fdotcom} \% 2 \mathrm{~F}$ client_service\%2Frisk\%2Fworking\%2520papers\%2F53_risk_paper_schmalenbachsurvey.ashx\&usg=AFQjCNEOloXyM5z3zcp7gM-nwWgGlqKOgQ\&sig2=homBhB8 ZHOs2wxy2MuUsrA

[5] Paquin, R., Powering the energy industry of the future by mitigating risk, Aberdeen Group, 2015, http://enablon.com/wp-content/uploads/_mediavault/2015/04/curatorpdf-10236-CUR-RR-Energy-Risk-Management.pdf

[6] Risk Intelligence in the Energy\&Resources Industry. Enterprise Risk Management Benchmark Survey, available at https://www2.deloitte.com/content/dam/Deloitte/fpc/ Documents/secteurs/energie-et-ressources/deloitte_etude_risk-intelligence-energy-ressources-industry_juin-2014.pdf 
[7] Executive Perspectives on Top Risks for 2015: Research conducted by North Carolina State University's ERM Initiative and Protiviti, available at http://www.protiviti.com/ en-US/Documents/Surveys/NC-State-Protiviti-Survey-Top-Risks-2015.pdf

[8] Operational Risk Management in the Energy Industry, 2014, available at http://www. managementsolutions.com/PDF/ENG/Operational-Risk-Energy.pdf

[9] Risk Quantification and Risk Management in Renewable Energy Projects, 2011, http:// iea-retd.org/wp-content/uploads/2011/11/RISK-IEA-RETD-2011-6.pdf

[10] Pindyck, R.S. \& Rubinfeld, D.L., Microeconomics, Prentice Hall: New Jersey, 2000.

[11] Vilenskij, V.P., The impact of risk uncertainty on the the effectiveness of investment projects, [in Russian]. Economic and Mathematical Methods, 4(38), pp. 24-31, 2002.

[12] Socio-economic forecasting of territorial systems development, [in Russian]. In Ural Branch of the Russian Academy of Sciences, eds H.N. Gizatullin \& A.I. Tatarkin, Ekaterinburg, 2001.

[13] Gitelman, L.D. \& Kozhevnikov, M.V., Risks of systemic transformation in energy companies. WIT Transactions on Ecology and the Environment, 192, pp. 357-365, 2015.

[14] Gitelman, L.D., Volkova, I.O., Kozhevnikov, M.V. \& Rostik, O.M., Organization of the innovation process in the power company, [in Russian], Economy: Moscow, 2014. https://doi.org/10.2495/ECO150321

[15] Bolado, R., Gracceva, F., Zeniewski, P., Zastera, P., Vanhoorn, L. \& Mengolini, A., Best practices and methodological guidelines for conducting gas risk assessments, 2012, https://ec.europa.eu/energy/sites/ener/files/documents/jrc68735_best_practices_and_ methodological_guidelines_for_conducting_gas_risk_assessments.pdf

[16] Fallon, W., Calculation Value-at-Risk. The Wharton Financial Institutions Center Working Paper, 1996, http://citeseerx.ist.psu.edu/viewdoc/download?doi=10.1.1.128.1283\&rep=rep1 \&type $=$ pdf

[17] Jones, J.C., Design Methods, 2nd edn., Wiley: Oxford, 1992.

[18] Moskvin, V., Project risk management by means of network models, [in Russian]. Investments in Russia, 10, pp. 27-37, 2002. 